\title{
Hemoperitoneo por linfoma em raiz mesentérica em equino
}

\author{
Hemoperitoneum caused by mesenteric root lymphoma in equine
}

\author{
Sofia Cicolo da Silva, Maria Eduarda Moreira Volpato, Julio David Spagnolo, Luciana Neves Torres, Vivian Fratti \\ Penna Ríspoli, Paulo Henrique dos Santos Castro, Aline de Matos Curvelo Barros, Carla Bargi Belli* \\ Faculdade de Medicina Veterinária e Zootecnia, Universidade de São Paulo (FMVZ-USP), São Paulo, SP
}

\section{Resumo}

Hemoperitoneo é o acúmulo de sangue na cavidade peritoneal, uma condição pouco relatada na espécie equina.Relata-seaquiocasodeumequino,QuartodeMilha, macho, 6 anos de idade, com queixa de edema recorrente em bolsa escrotal, distensão abdominal e alterações em auscultação pulmonar. 0 exame físico revelou baixo escore corporal, taquicardia, mucosas congestas e distensão abdominal. Realizou-se abdominocentese, onde foi observado líquido peritoneal sanguinolento, com 5\% de hematócrito, proteína 2 g/dL, 24.900 de células nucleadas e lactato $18,6 \mathrm{mmol} / \mathrm{L}$. No ultrassom abdominal, notou-se grande quantidade de líquido com presença de fibrina e baço com superfície irregular, de tamanho reduzido e afastado da parede abdominal. Indicou-se uma laparotomia exploratória, onde, além de grande quantidade de líquido sanguinolento, observouse a presença de formação tumoral em porção distal do jejuno, estendendo-se desde a raiz mesentérica até a junção com a alça intestinal. Devido à impossibilidade de remoção cirúrgica, indicou-se a eutanásia. Durante a necropsia, além da tumoração, havia também aumento de linfonodos mediastinais. 0 exame histopatológico indicou linfoma na forma multicêntrica. 0 incomum do caso é o acometimento da raiz mesentérica e o desenvolvimento de distensão abdominal e hemoperitoneo. 0 diagnóstico definitivo com o animal vivo é difícil, porém neste caso foi possível devido à laparotomia exploratória. Concluise que o linfoma deve ser considerado como diagnóstico diferencial em cavalos com hemoperitoneo.

Palavras-chave: Hemoperitoneo. Linfoma. Equino. Raiz do mesentério.

\begin{abstract}
Hemoperitoneum is the presence of blood in the peritoneal cavity, and it is rarely reported in equines. This is a case report of a stallion, 6 years old, Quarter Horse, presenting recurrent edema in scrotum, abdominal distension, and changes in pulmonary auscultation. Physical exam showed low body condition, tachycardia, and congest mucous membrane. Abdominocentesis was performed, where blood peritoneal fluid was observed, with 5\% hematocrit, $2 \mathrm{~g} / \mathrm{dL}$
\end{abstract}


protein, 24,900 nucleated cells and lactate $18.6 \mathrm{mmol} / \mathrm{L}$. Abdominal ultrasound revealed a large amount of fluid with fibrin, and spleen with irregular surface, of reduced size and away from the abdominal wall. An exploratory laparotomy was indicated, where, in addition to a large amount of bloody fluid, tumoral formation was observed in the distal portion of the jejunum, extending from the mesenteric root to the junction with the intestinal loop. Due to the impossibility of surgical removal, euthanasia was indicated. During necropsy, in addition to the tumor, there was also an increase in mediastinal lymph nodes. Histopathological examination indicated lymphoma in the multicentric form. The uncommon of this case is the involvement of the mesenteric root and the development of abdominal distension and hemoperitoneum. The definitive diagnosis with the animal still alive is difficult, but in this case it was possible due to exploratory laparotomy. We conclude that lymphoma should be considered as a differential diagnosis in horses with hemoperitoneum.

Keywords: Hemoperitoneum. Lymphoma. Equine. Root of the mesentery

\section{Introdução}

Hemoperitoneo é o acúmulo anormal de sangue na cavidade peritoneal. A ampla possibilidade de causas e a severidade das manifestações requerem uma interpretação cuidadosa dos achados físicos e laboratoriais. O histórico do animal é de extrema importância no direcionamento da conduta clínica, assim como os resultados de procedimentos como abdominocentese e ultrassom abdominal (Pusterla et al., 2005).

A ocorrência de hemoperitoneo pode ser secundária à ruptura esplênica ou hepática, ruptura de artérias mesentéricas por migração larval, de artéria uterina durante o parto, coagulopatias e lesões neoplásicas ou abscessos (Pusterla et al., 2005; Dechant et al., 2006).

Mogg et al. (2006) relataram hemorragias próximas ao momento do parto e hemoperitoneo em éguas como consequência da ruptura da artéria uterina ou ruptura uterina.

Dechant et al. (2006) notaram, em um estudo retrospectivo de 67 casos de hemoperitoneo, que cavalos Puro Sangue Inglês eram os mais acometidos, seguidos pelos Árabes, Quarto de Milha, cavalos de salto, Appaloosas e outras raças. As fêmeas foram as mais acometidas, seguidas por cavalos castrados e, por último, garanhões. As causas mais comuns foram trauma, neoplasia, ruptura da artéria uterina, injúria mesentérica e coagulopatia intravascular disseminada. Dos 67 casos, 51\% receberam alta, $37 \%$ foram eutanasiados e $12 \%$ vieram a óbito. As manifestações clínicas mais comuns foram desconforto abdominal e choque, além de membranas pálidas, aumento de frequência cardíaca e respiratória, baixa de hematócrito e de proteína.

Já Pusterla et al. (2005) relataram 19 cavalos com hemoperitoneo agudo e as principais causas foram idiopática, hematoma em baço com sangramento de cápsula, sangramentos do trato reprodutivo, hemangiossarcoma multicêntrico e amiloidose sistêmica. Os animais afetados tinham de 4 a 32 anos. As manifestações clínicas observadas foram depressão, taquicardia, taquipneia, mucosas pálidas, prolongamento do tempo de preenchimento capilar, dor abdominal, distensão abdominal, sudorese, ataxia e tumoração no ligamento largo na palpação retal. Nos exames laboratoriais foram encontrados azotemia, hipocalemia e aumento da creatinoquinasse. 0 diagnóstico foi baseado nos achados da abdominocentese, ultrassonografia abdominal e achados post-mortem.

Mendoza et al. (2012) descrevem um caso de hemoperitoneo causado por ruptura espontânea do baço em um equino que apresentava dor abdominal, fraqueza e sudorese. Ao exame ultrassonográfico foi observada presença de líquido heterogêneo livre em abdômen e uma estrutura intrabdominal com ecogenicidade semelhante ao baço.

Embora a real frequência do mesmo em equinos seja desconhecida, esta condição tem sido pouco relatada nesta espécie.

\section{Relato do caso}

Relata-se aqui o caso de um equino, Quarto de Milha, macho, não castrado, 6 anos de idade, encaminhado ao hospital veterinário com queixa de edema recorrente em bolsa escrotal, associado 
à distensão abdominal e alterações em auscultação pulmonar.

0 médico veterinário que encaminhou o animal realizou previamente um exame ultrassonográfico e encontrou grande presença de líquido livre na cavidade com características de heterogeneidade que, após a abdominocentese, verificou-se ter aspecto sanguinolento.

No hospital veterinário, o exame físico revelou baixo escore corporal, taquicardia, mucosas congestas, auscultação pulmonar com reverberação de ruídos cardíacos e intestinais, e distensão abdominal. No hemograma havia neutrófilos hipersegmentados, aumento de monócitos (1.068) e de fibrinogênio $(600 \mathrm{mg} / \mathrm{dl})$. Também havia diminuição de albumina $(1,82 \mathrm{~g} /$ dl) e aumento de bilirrubina indireta $(6,47 \mathrm{mg} / \mathrm{dl})$. No perfil renal identificou-se aumento de uréia $(73,7 \mathrm{mg} / \mathrm{dl})$.

Realizou-se abdominocentese, onde foi observado líquido peritoneal de aspecto sanguinolento, com 5\% de hematócrito, proteína $2 \mathrm{~g} / \mathrm{dL}, 24.900$ de contagem de células nucleadas e lactato $18,6 \mathrm{mmol} / \mathrm{L}$.

No ultrassom abdominal, notou-se grande quantidade de líquido com presença de fibrina, baço com superfície irregular, de tamanho reduzido e afastado da parede abdominal, e alças intestinais com pouca quantidade de conteúdo alimentar.

Diante das alterações observadas, indicou-se uma laparotomia exploratória para identificar a causa do hemoperitoneo. Durante o procedimento cirúrgico, ao realizar a incisão na linha média abdominal, ocorreu drenagem de grande volume de líquido sanguinolento. Na exploração da cavidade, observou-se a presença de formação tumoral em porção distal do jejuno desde a raiz mesentérica até a junção do mesentério com a alça intestinal.

Devido à extensão da formação e à impossibilidade de remoção cirúrgica, associado ao sangramento incontrolável, indicou-se a eutanásia do animal.

Durante a necropsia, além da tumoração evidenciada na laparotomia (Figura 1), havia também aumento de linfonodos mediastinais. Foi colhido material para exame histopatológico, onde foi diagnosticado linfoma em sua forma multicêntrica.

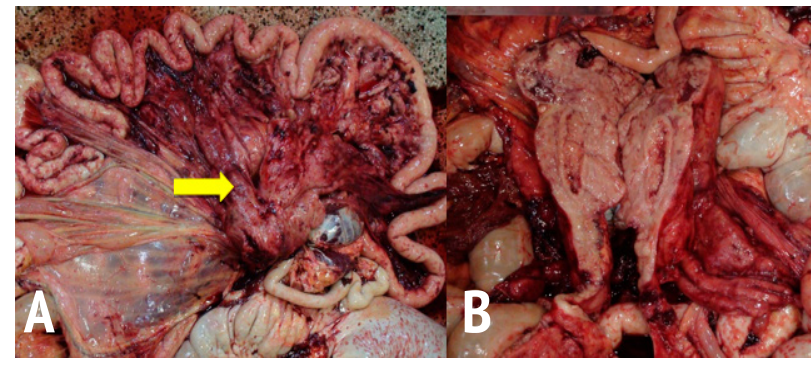

Figura 1 - Fotos da necropsia do animal do caso relatado. A - Tumoração no mesentério (seta). B - Secção longiotudinal do linfoma.

$\mathrm{Na}$ maioria dos relatos de hemoperitoneo (Pusterla et al., 2005; Dechant et al., 2006), os achados físicos e laboratoriais são semelhantes, estando principalmente relacionados com a perda de sangue, além dos relacionados com a causa de base. No caso aqui relatado, essas alterações também puderam ser observadas (hipoalbuminemia, hiperbilirrubinemia e presença de sangue na cavidade abdominal). 0 que diferiu neste caso foi a presença de grande aumento do lactato peritoneal, o que indica alteração vascular para alguma estrutura abdominal.

Segundo a literatura, o que mais ajuda a diferenciar a causa do hemoperitoneo são os achados ultrassonográficos (Pusterla et al., 2005; Mendoza et al., 2012), por isso esse exame é de extrema importância diagnóstica para auxiliar o clínico a escolher as condutas terapêuticas e determinar o prognóstico. Neste caso não foi possível indicar a causa exata, mas a ultrassonografia também foi importante para a exclusão de outras causas e para ajudar no encaminhamento.

Apesar de as neoplasias serem sempre uma possibilidade diagnóstica a se considerar, as manifestações clínicas apresentadas em casos de hemoperitoneo são inespecíficas (Pusterla et al., 2005). Nesses casos, muitas vezes o clínico tende a pensar em outros diagnósticos mais frequentes na espécie.

Os achados laboratoriais também tendem a ser inespecíficos, como no caso relatado nesse trabalho, que poderia ser compatível com uma peritonite ou um processo infeccioso abdominal, que também são frequentes na síndrome do 
abdômen agudo (cólica), muito comum na espécie equina. Por isso, o exame ultrassonográfico e a laparotomia exploratória são ferramentas muito importantes, nesse caso essenciais para o correto diagnóstico da causa do hemoperitoneo.

De acordo com Durham et al. (2012), o linfoma é a neoplasia mais comum do sistema hemolinfático em equinos, mas relatos de casos ou estudos retrospectivos são publicados com pouca frequência. Essa neoplasia pode acometer equinos de qualquer idade, porém o mais comum é em animais de 4 a 10 anos (Taintor e Schleis, 2011), compatível com a idade do cavalo do caso aqui relatado.

Segundo Parodi (2001), os linfomas formam um grupo heterogêneo de neoplasia com morfologia variável, diversas apresentações clínicas, e prognóstico e tratamentos clínicos variados, podendo ser classificados em multicêntricos, alimentares, mediastinais, cutâneos ou solitários (Taintor e Schleis, 2011). 0 incomum deste caso foi o acometimento da raiz mesentérica e o desenvolvimento de distensão abdominal e hemoperitoneo, o que é pouco relatado na literatura.

As manifestações clínicas nos cavalos com linfoma não são específicas e variam muito dependendo dos órgãos afetados. Perda de peso e edema ventral são as alterações físicas mais frequentes nos casos de linfoma. Hiperfibrinogenemia, hipoalbuminemia, anemia, leucemia, hiperglobulinemia e trombocitopenia são os achados laboratoriais mais comuns (Meyer et al., 2006), sendo alguns também observados neste caso. Embora bastante inespecíficos, a associação de emagrecimento e hipoalbuminemia ao caso de hemoperitoneo leva à forte suspeita de envolvimento de uma neoplasia.

Dependendo da localização, o diagnóstico definitivo do linfoma com o animal vivo é difícil, porém neste caso foi possível devido à laparotomia exploratória. 0 prognóstico de cavalos com linfoma depende da forma e do estágio do mesmo, porém óbito ou eutanásia são as evoluções mais observadas. Dentre as opções de tratamento disponíveis, há excisão cirúrgica, radioterapia ou quimioterapia (Taintor e Schleis, 2011)

No Brasil, o acesso a tratamento com radiação e fármacos quimioterápicos para equinos é difícil e muitas vezes não é uma opção de tratamento viável. Quando as manifestações clínicas são notadas, muitas vezes a neoplasia já acometeu outras estruturas importantes, com comprometimento vascular, ou apresenta grandes dimensões, o que a torna inoperável, levando a optar-se pela eutanásia para poupar o sofrimento do animal. Esse foi o caso do animal aqui descrito, já que não havia possibilidade cirúrgica de retirada da formação tumoral, além de já haver comprometimento vascular nas alças.

\section{Conclusão}

Conclui-se que o linfoma deve ser considerado como diagnóstico diferencial em cavalos com hemoperitoneo, pois um correto diagnóstico e prognóstico é essencial para decidir o tratamento a ser realizado.

\section{Referências}

Dechant JE, Nieto JE, Le Jeune SS. Hemoperitoneum in horses: 67 cases (1989-2004). J Am Vet Med Assoc. 2006;229(2):253-8.

Durham AC, Pillitteri CA, Myint MS, Valli VE. Two hundred three cases of equine lymphoma classified according to the World Health Organization (WHO) Classification Criteria. Vet Pathol. 2012;50(1):86-93.

Mendoza FJ, Valdes MA, Jimenez S, Caparros M, Enriquez F, Barsnick R, et al. Hemoperitoneum secondary to splenic rupture in a mare. Pferdeheilkunde. 2012;28(3):306-9.

Meyer J, Delay J, Bienzle D. Clinical, laboratory, and histopathologic features of equine lymphoma. Vet Pathol. 2006;43(6):914-24.

Mogg TD, Hart J, Wearn J. Postpartum hemoperitoneum and septic peritonitis in a Thoroughbred mare. Vet Clin North Am Equine Pract. 2006;22(1):61-71.

Parodi AL. Classification of malignant lymphoma in domestic animals: history and conceptual evolution. Eur J Vet Pathol. 2001;7(2):43-50. 
Pusterla N, Fecteau ME, Madigan JE, Wilson WD, Magdesian KG. Acute hemoperitoneum in horses: a review of 19 cases (1992-2003). J Vet Intern Med. 2010;19(3):344-7.

Taintor J, Schleis S. Equine lymphoma. Equine Vet Educ. 2011;23(4):205-13. 